\title{
Stressors and Coping Strategies among Neonates' Mothers Admitted at Neonatal Intensive Care Unit
}

\author{
Gehad Ramadan Ebrahim Hamoud ${ }^{1}$, Samar Mabrook El nahrawy ${ }^{2}$ Essmat Mohammed \\ Gemeay $^{3}$ \\ ${ }^{1}$ Bachelor Degree of Nursing, Faculty of Nursing, Tanta University, Egypt. \\ ${ }^{2}$ Lecturer of psychiatric mental health Nursing Faculty of Nursing, Tanta University, Egypt. \\ ${ }^{3}$ Prof. of psychiatric mental health Nursing Faculty of Nursing, Tanta University, Egypt.
}

Abstract: Back ground: The birth of a neonate that needs care in a neonatal intensive care unit (NICU) is one of the most stressful experiences for the mothers. The abrupt transition of baby from the protected environment of the womb to the pressured environment of neonatal intensive care unit present mother with a wide range of stressors. Aim: The study aimed to assess stressors and coping strategies among neonates' mothers admitted at Neonatal Intensive Care Unit. Research Design: The study followed a Descriptive research design to achieve the aim of the present study. Setting: The study was conducted at Neonatal Intensive Care Unit of Tanta University Hospital. The study subjects: The subjects of the study were Convenience sampling of 120 neonates' mothers admitted at Neonatal Intensive Care Unit. Tools: Data was collected by using two tools. 1) Parental Stressor Scale; 2) cope scale. Results: According to their total level of parental stressor. It found that about half of the studied mothers were moderately stressful, while (1.7\%) Of the studied mothers were not at all stressful. The mean score of the total level of parental stressor is (196.78 $\mathbf{5 . 9 0 6 )}$. According to their total level of utilization of coping strategies. It found that more than half about $\mathbf{6 4 . 2 \%}$ of the studied mothers had moderate utilization of coping strategies. Conclusion: There was statistically Correlation between total score of Stressor domains and total utilization of coping strategies score among the studied mothers. Recommendation: Based on the result of this study, it was recommended that the nurses at all levels need to have specialized knowledge and training, Conducting training program for nurses about stressors facing mothers and different strategies to deal with it.

Key words: Stress, Stressors, and Coping Strategies. 


\section{Introduction}

Motherhood is the most crucial and immediate environment in which the neonate survives and develops. The birth of neonate that requires neonatal care is the one that has the potential to cause considerable amount of stress and anxiety for mothers. The mother-infant bonding process that occurs during the newborn period establishes the foundation for a lifelong relationship. This typical process does not occur when the neonate spends the first several weeks or months in the Neonatal Intensive Care Unit (NICU) ${ }^{(\mathbf{1})}$.

Mothers experience feeling of guilt, responsibility, failure, and shame about their neonate's hospitalization. As a result, they have a much more difficult time bonding with their neonate, since they were not the primary caretakers for them. Feelings of separation during their neonate's time in the NICU can lead to emotional distance as their neonate grows up, and even disturb neurological development of the neonate ${ }^{(2)}$.

There are three broad categories of stressors that mothers experience while having a neonate infant in the NICU, these are psychological, social, and environmental. stressors is the most common one which include emotional exhaustion as a result of birth of an ill neonate, which may lead to stress, loss of control, helplessness, changing mother role and lead to barriers in mothers-neonates interactions that appear to have a long-term impact on motherhood $^{(3)}$.

Stressors such as struggling to meet the demands of other children in the home, transfer of mother role to NICU medical team, transportation barriers, financial strain, and ineffective patterns of communication among health care providers $^{(4)}$.

While the environmental stressors of the neonatal intensive care unit (NICU) serves as a significant source of stress for mothers. Neonatal units are often burdened with loud sounds, unpleasant sights and procedures, and crowds of health care professionals $^{(\mathbf{5})}$.

Mother who had an experience in NICU, may use coping strategies to overcome the situation. The word coping generally refer to adaptive coping mechanism that helps to reduce stressors. Coping mechanism need to be positive to lead to a mentally healthy life style. However, some strategies may actually increase stress, and in turn may be 
maladaptive $^{(6)}$.

Coping can be defined as an effort to manage and overcome demands and critical events that pose a challenge, threat, harm, loss, or benefit to a person there are two types of coping but conceptual distinction is between assimilative and accommodative coping, Assimilative coping implies tenacious goal pursuit, and accommodative coping flexible goal adjustment. Similarly, the terms "primary control" versus "secondary control" or "mastery" versus "meaning" (7).

Coping process have important role that help to prevent possible trouble. Preventive coping is not born out of an acute stress situation. It is not sparked by state anxiety, but rather by some level of trait worry, or at least reasonable concern about the dangers of life. General "coping selfefficacy" seems to be a good personal prerequisite to plan and initiate successfully multifarious preventive actions that help build up resilience against threatening non normative life events in the distant future ${ }^{(8)}$.

Among the unhealthy coping mechanisms are avoid the object of stressors, being passive aggressive, using suppression and going to the extreme with your emotions. While the positive coping mechanisms include seeking help from supportive people ${ }^{(9)}$.

Nurses are identified as a source of support by mothers. As most mothers described themselves as dependent on the nurses to care for their neonate, determines role of the mothers that they are taking of neonate's management. Very important to include mothers into the creation of the care plan and decision making process which improve care provided to the neonates. Mother's voice and soft music transfer love, emotions and wisdom and thus augur long term developmental benefits ${ }^{(10)}$.

Mother stressors in NICU are often a neglected area. Most of the care giving is centered to neonates. Quantifying stressors levels of mothers and identifying the greatest environmental stressor by understanding the aspects of neonates, mothers and the environment that can cause stressors may be useful for assisting the health personnel in targeting a complete family centered care and thus improving quality of life of the neonates .The current study aimed to assess stressors and coping strategies among neonates' mothers admitted at Neonatal Intensive Care Unit ${ }^{(11)}$. 


\section{Aim of the study}

\section{The aim of this study was to:}

Assess stressors and coping strategies among neonates' mothers admitted at Neonatal Intensive Care Unit.

\section{Research question;}

1. What are stressors and coping strategies of neonates' mothers admitted at Neonatal Intensive Care Unit?

\section{Subjects and Method}

\section{Subjects}

\section{Study Design:}

Descriptive research design was used.

\section{Study Setting:-}

The study was conducted at Neonatal Intensive Care Unit of Tanta University Hospital which affiliated to the Ministry of High Education.

\section{Subjects:-}

Convenience sampling of 120 neonates' mothers admitted at Neonatal Intensive Care Unit.

\section{Tools of data collection:-}

To achieve the aim of this study, the following tools were used;

\section{Tool I:- Structural interview schedule.}

Socio-demographic data to collect information of neonate's mothers.
Tool II: - Parental Stressor Scale: ${ }^{(12)}$

The scale contains 46 items, corresponding to four subscales which are:

a) Unfamiliar Sights and sounds for equipment in Neonatal Intensive Care Unit.

b) Appearance and behavior of the neonate.

c) Impact on parents' role and their relationship with their neonates.

d) Mothers' relationship and communication with the staff.

Mothers will be asked to rate each item according to how stressful the situation for them. It's scored on a 4-point Likert scale ranging from 1 point for "mild stress", 2 points for "moderate stress", 3 points for "severe stressful".

Each mother can receive score ranging from 46 to 230 degree, Evaluation of this questionnaire will be as follow:-
A- (46-100) $\Longrightarrow$ not at all stress
B- (101-150) $\longrightarrow$ mild stress.
C- (151- 200) $\longrightarrow$ fairly moderate stress.
D- (201-230) $\longrightarrow$ severe stress.

Tool III: - Cope Scale : ${ }^{13)}$

The cope scale is consisting of 28 items distributed in 14 sub items, each of which assesses the degree to which a respondent utilizes a specific coping strategy as: 
- Factors related to active coping such as: Taking action to try to make the situation better.

- Aspects related to planning such as: Trying to come up with a strategy about what to do.

- Positive Reframing such as: Trying to see it in a different light, to make it seem more positive.

- Acceptance such as: Accepting the reality of the fact that it has happened.

- Humors such as: Making jokes about it.

- Religion such as: Trying to find comfort in my religion or spiritual beliefs.

- Using Emotional Support such as: Getting comfort and understanding from someone.

- Using Instrumental Support such as: Getting help and advice from other people.

- Self-Distraction such as: Turning to work or other activities to take my mind off things.

- Denial item such as: Saying 'this isn't red.

- Venting such as: Saying things to let my unpleasant feelings escape.
- Substance Use such as: Using alcohol or other drugs to make myself feel better.

- Behavioral Disengagement such as: Giving up trying to deal with it.

- Self-Blame such as: Criticizing myself.

\section{Scoring system:}

1- Each item is scored on a 3-point Likert scale, ranging from 1 (Not doing this at all) to 3 (Doing this a lot).

2- Each patient can receive score ranging from 28 to 112 grades, Evaluation of this questionnaire will be as follow:-

\section{Level of utilization of coping strategies:-}

- (<60\%) Mothers slight utilize of coping strategies.

- (60 to $75 \%)$ Mothers have moderate utilize of coping strategies.

- (> 75\%) Mothers have great utilize of coping strategies.

\section{Method}

1- An official permissions was obtained from Neonatal Intensive Care Unit of Tanta University.

2-Ethical considerations were obtained from neonates' mothers after explaining the aim of the study and their right to withdraw from the study at any time. 
Confidentiality and privacy of the information obtained from them will be maintained.

3-Tool (I, II, III) was developed by the researcher after review of recent literature.

4-The tools of the study was tested for content and validity by a group of five experts in the psychiatric nursing field, required correction will be done until the used tools approved as being valid.

5- Pilot study was conducted on $10 \%$ of mothers after taking their approval to ascertain the clarity, applicability and feasibility of the study tools. The necessary modifications will be done according to pilot study. The pilot study will be excluded from the original sample.

6-The interview schedule was administered individually to each mother and interviewed in privacy by the researcher using (three tools) within 30 minutes.

7-The researcher was assessed stress level of neonates' mothers admitted at Neonatal Intensive Care Unit using (tool II).

8-The researcher was assessed coping of neonates' mothers admitted at Neonatal Intensive Care Unit using (tool III).

9-Data was collected within 6 months.

\section{Statistical analysis:}

The collected data were organized, tabulated and statistically analyzed using SPSS software statistical computer package version 26. For quantitative data, the range, mean and standard deviation were calculated. For qualitative data, comparison was done using Chi-square test $\left(\chi^{2}\right)$

Correlation between variables was evaluated using Pearson and Spearman's correlation coefficient r. A significance was adopted at $\mathrm{P}<0.05$ for interpretation of results of tests of significance $(*)$. Also, a highly significance was adopted at $\mathrm{P}<0.01$ for interpretation of results of tests of significance $(* *)$

\section{Results}

Table (1) shows distribution of the studied mothers' sociodemographic characteristics. It showed that the majority of sample approximately $65.8 \%$ of mothers aged 20$<30$ years old.

The mean age of the studied mothers is $27.03 \pm 4.278$ year's .Regarding the gestational age the mean age. It was found to be $\mathbf{3 5 . 1 9 \pm 0 . 6 3 9}$. Also, near half of the studied mothers $(48.3 \%)$ had diplome in educational level. Regarding occupation the table showed that approximately $(63.3 \%)$ of the studied 
mothers were house wife comparing $(1.7 \%)$ of them were lawyers .Regarding age of neonates the majority of neonates were $58.3 \%$ aged $7-<14$ days compared with $5.8 \%$ aged $<7$ days .The mean age of neonates is $12.66 \pm 5.683$ day. the table showed that the majority of neonates Stay length in NICU (in days) is $46.7 \%$ of neonates were 7-<14 days compared with $5.8 \%$ were less than or equal 20 days. The mean of Days of hospitalization is $9.93 \pm 5.331$ days .Regarding Pregnancy problems of studied mothers the majority $95.8 \%$ didn't have any problems .Regarding Child birth type $73.3 \%$ of studied mothers were Caesarean labor. The mean of Number of living children is $2.90 \pm 0.991$ child the mean of Birth weight is $\mathbf{1 . 9 3} \pm \mathbf{0 . 1 2 7}$ kilo grams. The mean of Number of delivery is $3.25 \pm 1.117$ time. Regarding Number of NICU visits the majority of studied mothers visits were $50.8 \%$ less than 7 days compared with $2.5 \%$ are $\geq 21$ days. The mean of Number of NICU visits is $7.78 \pm 4.595$ times. The majority of neonates diagnosis (60.8\%) had breathing difficulty comparing with (3.3\%) had Pneumonia.
Table (2): this table illustrates the total mean scores of parental stressor domains of the studied mothers. It shows that The Total mean scores of parental stressor domains of the studied mothers in relation to Un familiar Sights were (22.21 $\pm \mathbf{1 . 5 8 7})$, Baby looks and behaves were (86.31 \pm 3.159$)$, Relations and

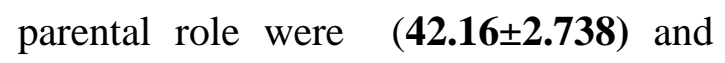
$\mathbf{( 5 0 . 1 7 \pm 2 . 9 8 5 )}$ related to Staff behavior's and communications

Table (3): this table shows the Distribution of the studied mothers according to their total level of parental stressor. It found that half of the studied subjects $\mathbf{( 5 0 . 0 \% )}$ were moderately stressful, While (1.7\%)Of the studied mothers were not at all stressful. The mean score of the total level of parental stressor is $\mathbf{( 1 9 6 . 7 8} \pm \mathbf{5 . 9 0 6})$.

Table (4): this table reveales distribution of the studied mothers according to their total level of utilization of coping strategies. It shows that less than half $\mathbf{3 4 . 2 \%}$ of the studied subjects(34.2\%) had slight utilization of coping strategies level, while more than half of the studied subjects $(\mathbf{6 4 . 2 \%})$ had moderate utilization of coping strategies and about $\mathbf{( 1 . 7 \% )}$ of the studied mothers had great utilization of coping strategies about Coping 
Strategies Among Neonates' Mothers

Admitted at Neonatal Intensive Care

Unit. The mean score of Total utilization

of coping strategies level is

(80.46 \pm 4.463$)$.

Table (5): this table illustrates the correlation between total score of Stressor domains and total utilization of coping strategies score among the studied mothers. It found that there were a significant negative mild correlation between the total score of coping strategies and the two stressor domains

( un familiar Sights and sounds, and Baby looks and behaves).on the other hand, there was non-significant positive mild correlation between the total score of coping strategies and Relations and parental role stressor domain .Also there was a negative non-significant mild correlation between the total score of coping strategies and Staff behavior's and communications Stressor domains. At the end there was a significant negative moderate correlation between the total utilization of coping strategies and the total stressor score of the studied mothers $(\mathrm{r}=-0.341, \mathrm{p}=0.026<0.05)$. 
Table (1): Distribution of the studied mothers' sociodemographic characteristics.

\begin{tabular}{|c|c|c|}
\hline \multirow[t]{2}{*}{ Characteristics } & \multicolumn{2}{|c|}{$\begin{array}{l}\text { The studied mothers } \\
(\mathrm{n}=120)\end{array}$} \\
\hline & $\mathbf{N}$ & $\%$ \\
\hline $\begin{array}{l}\text { Mother's age (in years) } \\
\text {. } \quad<20 \\
\text {. } 20-<30 \\
\text { } \quad \geq 30\end{array}$ & $\begin{array}{c}5 \\
79 \\
36\end{array}$ & $\begin{array}{c}4.2 \\
65.8 \\
30.0\end{array}$ \\
\hline $\begin{array}{c}\text { Range } \\
\text { Mean } \pm \text { SD }\end{array}$ & \multicolumn{2}{|c|}{$\begin{array}{c}(18-38) \\
27.03 \pm 4.278\end{array}$} \\
\hline $\begin{array}{r}\text { Gestational age (in weeks) } \\
\text { Range } \\
\text { Mean } \pm \text { SD }\end{array}$ & \multicolumn{2}{|c|}{$\begin{array}{c}(34-36) \\
35.19 \pm 0.639\end{array}$} \\
\hline $\begin{array}{l}\text { Marital status } \\
-\quad \text { Married }\end{array}$ & 120 & 100.0 \\
\hline $\begin{array}{l}\text { Educational level } \\
\text { - Read and write } \\
\text { - Secondary school } \\
\text { - Diplome } \\
\text { - Technical institute } \\
\text { - } \text { Bachelor }\end{array}$ & $\begin{array}{c}2 \\
5 \\
58 \\
18 \\
37\end{array}$ & $\begin{array}{c}1.7 \\
4.2 \\
48.3 \\
15.0 \\
30.8\end{array}$ \\
\hline $\begin{array}{ll}\text { Occupation } \\
\text { : } & \text { House wife } \\
\text { - } & \text { Teacher } \\
\text { - } & \text { Nursing } \\
\text { : } & \text { Engineer } \\
\text { - } & \text { Technician } \\
\text { - } & \text { Doctor } \\
\text { - Lawyer }\end{array}$ & $\begin{array}{l}76 \\
17 \\
15 \\
3 \\
4 \\
3 \\
2\end{array}$ & $\begin{array}{l}63.3 \\
14.2 \\
12.5 \\
2.5 \\
3.3 \\
2.5 \\
1.7\end{array}$ \\
\hline $\begin{array}{l}\text { Age of neonates (in days) } \\
:<7 \\
: 7-<14 \\
: 14-<21 \\
: \geq 21\end{array}$ & $\begin{array}{c}7 \\
70 \\
27 \\
16\end{array}$ & $\begin{array}{c}5.8 \\
58.3 \\
22.5 \\
13.3\end{array}$ \\
\hline $\begin{array}{c}\text { Range } \\
\text { Mean } \pm \text { SD }\end{array}$ & & \\
\hline 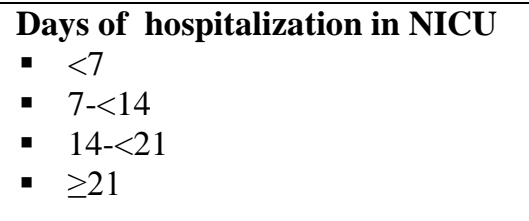 & $\begin{array}{c}39 \\
56 \\
18 \\
7\end{array}$ & $\begin{array}{c}32.5 \\
46.7 \\
15.0 \\
5.8\end{array}$ \\
\hline $\begin{array}{c}\text { Range } \\
\text { Mean } \pm \text { SD }\end{array}$ & & \\
\hline
\end{tabular}




\begin{tabular}{|c|c|c|}
\hline $\begin{array}{l}\text { Pregnancy problems } \\
\text { - None } \\
\text { - Gestational diabetes }\end{array}$ & $\begin{array}{c}115 \\
5\end{array}$ & $\begin{array}{c}95.8 \\
4.2\end{array}$ \\
\hline $\begin{array}{l}\text { Child birth type } \\
\text { - Normal } \\
\text { - } \quad \text { Caesarean } \\
\end{array}$ & $\begin{array}{l}32 \\
88 \\
\end{array}$ & $\begin{array}{l}26.7 \\
73.3 \\
\end{array}$ \\
\hline $\begin{array}{l}\text { Number of living children } \\
\text { Range } \\
\text { Mean } \pm \text { SD }\end{array}$ & \multicolumn{2}{|c|}{$\begin{array}{c}(1-5) \\
2.90 \pm 0.991\end{array}$} \\
\hline $\begin{array}{cc}\text { Birth weight (in Kg) } & \begin{array}{c}\text { Range } \\
\text { Mean } \pm \text { SD }\end{array} \\
\end{array}$ & \multicolumn{2}{|c|}{$\begin{array}{c}(1.00-2.00) \\
1.93 \pm 0.127\end{array}$} \\
\hline $\begin{array}{cc}\text { Number of delivery } & \text { Range } \\
\text { Mean } \pm \text { SD }\end{array}$ & \multicolumn{2}{|c|}{$\begin{array}{c}(1-6) \\
3.25 \pm 1.117\end{array}$} \\
\hline $\begin{array}{l}\text { Number of NICU visits } \\
\text { - } \quad<7 \\
\text { - } \quad 7-<14 \\
\text { - } \quad 14-<21 \\
\text { - } \quad \geq 21\end{array}$ & $\begin{array}{c}61 \\
43 \\
13 \\
3\end{array}$ & $\begin{array}{c}50.8 \\
35.8 \\
10.8 \\
2.5\end{array}$ \\
\hline $\begin{array}{c}\text { Range } \\
\text { Mean } \pm \text { SD }\end{array}$ & \multicolumn{2}{|c|}{$\begin{array}{c}(2-24) \\
7.78 \pm 4.595\end{array}$} \\
\hline $\begin{array}{l}\text { \# Diagnosis of infant } \\
\text { - Pneumonia } \\
\text { - Breathing difficulty } \\
\text { - } \text { Weight loss } \\
\text { - Yellowish neonatal }\end{array}$ & $\begin{array}{c}4 \\
73 \\
7 \\
39\end{array}$ & $\begin{array}{c}3.3 \\
60.8 \\
5.8 \\
32.5\end{array}$ \\
\hline
\end{tabular}

\# More than one answer was chosen.

Table (2): Total mean scores of parental stressor domains of the studied mothers.

\begin{tabular}{|l|c|c|}
\hline \multirow{2}{*}{ Parental Stressor domains } & \multicolumn{2}{|c|}{$\begin{array}{c}\text { The studied mothers } \\
(\mathbf{n = 1 2 0})\end{array}$} \\
\cline { 2 - 3 } & Range & Mean \pm SD \\
\hline 1. Un familiar Sights and sounds & $(17-24)$ & $22.21 \pm 1.587$ \\
\hline 2. Baby looks and behaves & $(79-92)$ & $86.31 \pm 3.159$ \\
\hline 3. Relations and parental role & $(38-47)$ & $42.16 \pm 2.738$ \\
\hline 4. Staff behavior's and communications & $(44-58)$ & $50.17 \pm 2.985$ \\
\hline
\end{tabular}

Table (3): Distribution of the studied mothers according to their total level of parental stressor.

\begin{tabular}{|l|c|c|}
\hline \multirow{2}{*}{$\begin{array}{c}\text { Total } \\
\text { Stressor } \\
\text { Level }\end{array}$} & \multicolumn{2}{|c|}{$\begin{array}{c}\text { The studied mothers } \\
(\mathbf{n = 1 2 0})\end{array}$} \\
\cline { 2 - 3 } & $\mathbf{N}$ & $\mathbf{\%}$ \\
\hline - Not at all stress & 2 & 1.7 \\
- Mild stress & 3 & 2.5 \\
- Moderate stress & 60 & 50.0 \\
- Severe stress & 55 & 45.8 \\
\hline
\end{tabular}




\begin{tabular}{|c|c|}
\hline Range & $(175-213)$ \\
Mean \pm SD & $196.78 \pm 5.906$ \\
\hline
\end{tabular}

Table (4): Distribution of the studied mothers according to their total level of utilization of coping strategies.

\begin{tabular}{|l|c|c|}
\hline \multirow{2}{*}{$\begin{array}{c}\text { Total utilization of } \\
\text { coping strategies level }\end{array}$} & \multicolumn{2}{|c|}{$\begin{array}{c}\text { The studied mothers } \\
(\mathbf{n = 1 2 0})\end{array}$} \\
\cline { 2 - 3 } - Slight & $\mathbf{N}$ & $\mathbf{\%}$ \\
- Moderate & 41 & 34.2 \\
- Great & 77 & 64.2 \\
& 2 & 1.7 \\
\hline Range & \multicolumn{2}{|c|}{$\mathbf{( 6 9 - 9 2 )}$} \\
Mean \pm SD & \multicolumn{2}{|c|}{$\mathbf{8 0 . 4 6 \pm 4 . 4 6 3}$} \\
\hline
\end{tabular}

Table (5): Correlation between total score of Stressor domains and total utilization of coping strategies score among the studied mothers.

\begin{tabular}{|c|c|c|}
\hline \multirow[t]{2}{*}{ Stressor domains } & \multicolumn{2}{|c|}{$\begin{array}{c}\text { Total utilization of } \\
\text { coping strategies score }\end{array}$} \\
\hline & $\mathbf{r}$ & $\mathbf{P}$ \\
\hline 1. Un familiar Sights and sounds & -0.184 & $0.044 *$ \\
\hline 2. Baby looks and behaves & -0.193 & $0.034 *$ \\
\hline 3. Relations and parental role & 0.096 & 0.297 \\
\hline 4. Staff behavior's and communications & -0.104 & 0.260 \\
\hline Total stressor score & -0.341 & $0.026 *$ \\
\hline
\end{tabular}




\section{DISCUSSION}

The present study was carried out to assess stressors and coping strategies among neonates' mothers admitted at Neonatal Intensive Care Unit. Because of mother is the most caregiver parent for the baby .This could be due to that the mother traditionally take more physical and emotional responsibility of care, also mother can tolerate her sons responsibility specially at the first year of age this finding supported by by(Jackson,2013) ${ }^{(\mathbf{1 4})}$ ,who stated that the mother experienced higher level of stress than any family members after birth of ill baby .this result in consistent with study conducted by (Matricardi \&Montorios, 2013) $^{(\mathbf{1 5 )}}$, they showed that mother and father response for the same level of trauma and stress after neonate's admission to NICU. As regards to socio- demographic characteristics for mother of neonate admitted at Neonatal Intensive Care Unit. Concerning to age group in the current study mean age group (18-38) most of age groups in current study 18 years old. Resulting in earlier and more frequent pregnancies. And also lack access to medical care may also result in premature birth and Neonatal Intensive Care Unit hospitalization.

As regard educational level ,the current study showed that ,the majority of mothers who had moderate level of education were likely increase risk of premature birth more than mothers of high education as they are more likely to increase gestational age ,this finding agreed with yang, who showed that education is an indicator of socio-economic status of person,when mother will educated influence her ability to access and use health care .Toward this respect, the current study showed more than half of studied subject had secondary school education ,this result agreed with (petite , 2016) ${ }^{(\mathbf{1 6})}$, who found that the high education play important role in healthy life style and prevent premature birth and his psychological effect on the mother.

As regards to job of mothers, the current study showed that more than half of studied mothers under this study was house wife that showed there weren't association between high physical work demand and low birth weight. This finding consistent with ( triche,2010) ${ }^{(\mathbf{1 7})}$, who stated that strong associations between high physical work demand and low birth weight also point out that the premature birth due to poorer working condition and job insecurity.

Regarding to gestational age of infant, the present study revealed that the majority gestational age of neonate was ranged from 34-36 week of gestation. This is confirmed with the study carried out by (De magistris et al. ,2010) ${ }^{(\mathbf{1 8 )}}$ who stated that ,stressed 
symptoms are associated with lower gestational age ,length stay at neonatal intensive care unit and severity of illness.

Regarding the Parent stressors scale subscales, the highest mean score belongs to the subscale of the infant's appearance and behaves (86.31 \pm 3.159$)$, followed by Staff behavior's and communications $(50.17 \pm 2.985)$ ,the parents' role alterations subscale mean score $(42.16 \pm 2.738)$ and then the sights and sounds subscale mean score $(22.21 \pm 1.587)$. Based on the results of the present study, it was determined that the area that causes the most stress for parents is their infant's appearance and behaviors. This result was similar to the finding of (Shields-Poe and Pinelli, 2011) ${ }^{(19)}$ who performed a study using the Parernt stressors scale: NICU and determined that the parents' greatest stress was due to their infant's appearance and behaviors. In another a study conducted by ( Preyda and Ardal,2014) ${ }^{(20)}$, that different from this study, who determined that the factor that creates the most stress for parents is parental role alterations.

Parents' mean score on the relation and parental role subscale was $(42.16 \pm 2.738)$. In other study conducted Franck et al, the mean score on the parental role subscale was found to be more than the current one. Similar to the study of (Franck et al, 2007) ${ }^{(21)}$, who was determined that parental role alterations cause the highest stress among parents. That inconsistent with this results which the effective area causing stress for mothers babies appearance and behaviors.

Parents' mean score on the UN familiar sights and sounds subscale was found to be $(22.21 \pm 1.587)$ in the presented study, which is lesser than the scores found in other studies. In the other study conducted, the mean score on the UN familiar sights and sounds subscale was found to be (2.08). Such high levels of stress reduced because of giving Knowledge of stress-related environmental resources in Tanta university neonatal intensive care units can help nurses reduce parents' levels of stress. For example, when parents are informed about the reasons for the use of monitors in neonatal intensive care units and when monitor alarm sound levels are adjusted to appropriate levels, the stress experienced by parents in this regard will decrease.

The stress levels of parents who received information from different sources about the condition of their babies were found to be lower than the stress levels of those who did not. In the study carried out by (Turan et al, 2016) ${ }^{(22)}$.parents were encouraged by nurses to receive information from different sources. It was determined at the end of the study that stress levels of parents who received information from different sources decreased. Knowledge acquisition is a strategy that reduces the fear and anxiety caused by obscurity Knowledge acquisition also 
provides the opportunity to establish control over the situation, and it is a good way to reduce mothers' stress levels. Another study determined that parents' understanding of quality nursing care included predictions and provisions by nurses of information that parents may need and the establishment of a positive relationship between them for this purpose. Regarding coping strategies employed by mothers of newborn babies when admitted to a neonatal care unit. The study revealed that mothers of preterm babies used praying, attachment to baby and acceptance of the situation as coping strategies.

Regarding this study, Participants of this study expressed faith that God could increase their strength to care for their babies, as well as overcome the stress caused by preterm delivery. It can be mentioned that participants of this study demonstrated personal prayers for thanksgiving and for God to relieve them of stress as well as healing their babies.

The study revealed that believing in the supernatural God can be used as one of the coping strategies at the time of difficulties. Mothers with new born babies admitted to NICU prayed to requesting grace and strength to take them through such hopeless experiences for their premature babies. This is consistent with the results of a study reported by (Arzani et al ,2015) ${ }^{(23)}$, who found that prayer was the most important strategy that mothers of new born ill babies used to cope.
Participants asked God to intercede and provide good health to their preterm babies.

The majority of these participants relied on God's mercy; hence, this was reflected in the religious background of the participants. Every participant expressed that they were either Christian or Muslim. This explained why they all depended on God to relieve them of the trauma they were going through. This is also in accordance with the study by ( Wachholtz et al ,2009) (24) who found that dependence on prayer by individuals who are facing a stressful event is very useful coping strategies.

Regarding coping with the infant's hospitalization, faith and trust in God seem essential for helping these women to bear the suffering they experience as a result of having an infant at the NICU. Among the mothers' coping, this is consistent with (Nolan, 2018) (25) who state that the use of such strategies allowed them to remain optimistic and continue to hope for the baby's recovery despite adversities. This Religiosity was a resource for emotion regulation in relation to the stressors, as was positive self-talk

Subjects in the present study found that attachment to their babies was through seeing their babies frequently as well as evidence of life, progress on babies and no regrets. The attachment to a baby differs from mother to mother. For admitted neonate to NICU, mother-baby bonding is usually interrupted by 
the baby's admission to a neonatal care unit, and this separation can affect the mother's attachment to the baby. Some mothers would prefer to stay away, because of fear and uncertainty, others would prefer seeing and touching their babies as well as looking after the treatment their babies receives from health care professionals. In this study, attachment was very important to mothers as these mothers demonstrated preference to remain beside their babies.

This current study revealed that closeness with the newborn has enormous benefits for the mothers' coping strategies. Flacking et al. mentioned that attachment of mothers to their baby increases and secures mother-infant bonding. Bonding also augments mothers' confidence and competence in the care of their preterm babies. This reduces chances of high levels of stress and anxiety as well as prevents depression in subjects. Mothers in this study experienced attachment to their babies by touching, seeing and cuddling their babies. These participants experienced joy and happiness, which helped to reduce fear in them a as well as prevent rejection of their ill new born babies; this is confirmed by a study which found that attachment of mother to baby leads to well-being of the mother as well as better growth and development in the preterm baby. However, participants in this study remained in the hospital, in the neonatal care unit, to bond with their babies. This is because they understood their responsibilities in the lives of their babies. Acceptance of the situation was matched to the concept of acceptance in the Brief cope model by (Carver, 1997) ${ }^{(\mathbf{1 3})}$. This means that participants tend to accept the realism of the situation, and accept living with the stressful situation, which enables coping.

According to literature, it is clearly stated that the use of preterm labour and delivery is un known. Therefore, mothers who deliver preterm babies should be prepared in order to be ready to accept the event of preterm delivery and hospital admission. This will enable them to cope better than when it happens when the mothers are unaware of the expectations. It becomes the responsibility of the health care staff to educate mothers during antenatal periods to educate and prepare mothers for unforeseen circumstances such as preterm labor, delivery and admission. This is noted by (Flacking, 2013) ${ }^{(26)}$.

Concerning stress levels experienced by parents of premature infants hospitalized in neonatal intensive care units is crucial for healthcare professionals working in intensive care units. Determining the factors that cause stress among parents and developing appropriate intervention protocols will help reduce the stress levels of parents and give parents the ability to cope with the complex neonatal intensive care environment this is agree with ( Sikorova,2012) ${ }^{(27)}$. 


\section{Recommendations}

\section{Based on the results of the present study the following recommendations were suggested for:}

\section{At mothers' level}

-The present study provides important information for mothers for newborn baby in NICU at Tanta university Hospital. This information can be used to prevent stress or facilitate adaptation and coping with regard to stress.

-Stress could potentially be reduced for mothers by health care providers giving more realistic estimates of when test or procedures will take place, and having a plan for how and when the results will be communicated.

-The mother have been educated on her infant's condition, treatment options, and ethical issues, so she was involved as much as possible in the decision making regarding her infant. Attention has been given to teaching the mother specific NICU care skills and techniques for use with her infant.

\section{At staff nurses' level}

-Staff should be educated on principle and methods of supporting mother during staying period in neonatal intensive care unit.
-The results of this study gave us a better understanding of what is stressful to parents and what they do to cope with these stressors while their child is hospitalized. This information can be used to help parents identify coping strategies and to develop interventions to help parents with coping.

-This study has identified strategies used by mothers to cope with stressors, and this information could be used to inform the development of an instrument to identify and evaluate the effectiveness of coping strategies for use in a larger population.

-It is unnecessary to provide a general intervention, further to what is already being practiced in the unit, with all parents. There are, however, some parents that do find the NICU environment more stressful, and they may benefit from increased clinical attention. Justification was provided for specific clinical attention to be targeted to the following areas.

-Engage in support group to help mother to connect with other who have similar problem and concern is very important issue.

-Appropriate and warm welcome for mother from the time of baby admission 
and teach some practice of special care, staff role and simple explanation of equipment .

Further researches need to be conducted to regarding how to measure parent coping during this time. The technology and availability of the Internet and social media has continued to advance. It is becoming increasingly common for mothers to share their stories on Facebook, Instagram, Twitter, and other platforms creation and sustain a healing environment with respect sensory exposure and experience.

\section{Reference}

1-Carolyn W. parental stress and coping during the hospitalization of a child : A dissertation submitted to the faculty at the University of North Carolina at Chapel Hill. 2015; 23(4): 1-21.

\section{2- Nair c, Girish G,and Jatana S. NICU}

Environment : Can we be Ignorant? sources of stress for parents. Journal of Critical care Nursing. 2008;2(2):346-54.

3- Dudek- Shriber L. Parent stress in the neonatal intensive care unit and the influence of parent and infant characteristics: Journal of Occupational Therapy. 2004; 58(4):509-20.

4- Agrawal R, and Gaur A. Parent stress in neonatal intensive care unit: an unattended aspect in medical care.
International Journal of Contemporary Pediatrics. 2017; 4(1):148-153.

\section{5-Elisa P, Fernanda V, Ignacia $M$,} Javier R, and Sergio A . Stress in parents of newborns hospitalized in a Neonatal Intensive Care Unit:Review of Pediatric nursing practitioner. 2017;88 (3):332-339.

6-Sikorova L, and Kucova J. The needs of mothers to newborns hospitalised in intensive care units: Biomed Paper of medical Faculty University of Palacky Olomouc Czech Repub. 2012;156 (3): 330-6.

7-Meyer E, Garcia C, Lester B, Zachariah $\mathrm{C}$, and McDonough $\mathrm{S}$. Family-based intervention improve maternal psychological well-being and feeding interaction of preterm infants: Journal of Pediatric Psychology. 1994; 93(1): 241-6.

\section{8-Craig J, Glick C, Phillips R, Hall SL,} Smith J, and Brown J. Recomendations for involving the family in developmental care of the NICU baby: Journal of Perinatology. 2015; 35(5): S5-S8.

9-Holditch D, and Miles M. Mother's stories about their experiences in the neonatal intensive care unit: Neonatal Network . 2000;19(8): 13-21. 
10-Turan T, Basbakkal Z, and Ozbek S.

Effect of nursing interventions on stressors of intensive care unit: Journal of Clinical Nursing. 2008; 17(2):2856-66.

\section{1-Friedman S, Yang S, Parsons S, and}

Amin J. Maternal mental health in the Neonatal Intensive Care Unit: Newborn screening critical congenital heart defect reviews. 2011; 12 (23):85-93.

\section{2-Sanguesa $\mathbf{P}$, Farkas $\mathbf{C}$, and Rochet $\mathbf{P}$.}

The relationship between maternal representations and interactive behavior with the mother's emotional state, perceived social support and the infant's risk level in a group of premature babies: Estudios internationals de Psicol university. 2014;35 (9):80-103.

\section{3-Matricardi S, Agostino R, Fedeli C,} and Montirosso R. Mothers are not fathers: differences between parents in the reduction of stress levels after a parental intervention in a NICU: Journal of Child Psychology and Psychiatry, 2013;102(3):8.

14-Pierrehumbert B, Ansermet F, and Muller-Nix C. Prematurity, maternal posttraumatic stress and consequences on the mother infant relationship : Early Human Development research . 2011;87(16):21-6.
15-Shaw R, St John N, Lilo E, et al. Prevention of traumatic stress in mothers with preterm infants: a randomized controlled trial: Pediatrics research. 2013;132(24):886-94.

16-Miles M, Funk S, and Kasper M. The stress response of mothers and fathers of preterms infant: Research of Nursing Health. 1992;15 (1):261-9.

17-Dutta S, Mahajan R, Agrawal SK, Nehra R, and Narang A. Stress in fathers of premature newborns admitted in a neonatal intensive care unit: Indian Pediatrics Journal . 2016; 53(4):311-3.

18-Chourasia N, Surianarayanan $\mathbf{P}$, Adhisivam B, and Vishnu B. NICU admissions and maternal stress levels: Indian Journal of Pediatrics. 2013; 80(5):380-4.

19-Singer LT, Salvator A, Guo S, Collin M, Lilien L, and Baley J. Maternal psychological distress and parenting stress after the birth of a very low-birthweight infant: Journal of American Medical Association. 1999;281(27) :799-805.

20-Andrea M. Emotional experiences of mothers of newborns Admitted to the neonatal intensive care unit: American Journal of Occupational Therapy 2016; 33(4): 52-60. 
21-Nirubaa U, and Manoji B.Maternal stress level when a baby is admitted to the neonatal intensive care unit at Teaching Hospital Jaffna and the influence of maternal and infant characteristics on this level: Sri Lanka Journal of Child Health, 2016; 45(2): 90-94.

\section{2- Nolan K., Camfield C and Camfield}

P. Coping with a child with Dravet Syndrome: Insights from families. Journal of Child Neurology; 2008, 23(1), 690-694.

\section{3- Moghaddam T, Alizadeh Sand}

Radfar M. Barriers of Parenting in Mothers with a Very Low- BirthWeight Preterm Infant, and their Coping Strategies: A Qualitative Study. International Journal of Pediatrics. 2017; 5(9): 5597-5608.

24-Bass L. What do parents need when their infant is a patient in

The NICU?: Neonatal Network;1999, 10(2):25-33 .

\section{5-Carter J, Mulder R, Bartram Aand}

Darlow B. Infants in a neonatal intensive care unit: Parental response: Archives of Disease in Childhood Fetal and Neonatal Edition; 2005, 90(1), F109-F113.
26-Lindberg B, Axelsson Kand ÖhrlingK. The birth of premature infants: Experiences from the fathers' perspective: Journal of Neonatal Nursing; 2007; 13(2), 142-149.

27-Petite AC. Mother emotional and posttraumatic reactions after preterm birth :the mother -infant interaction is at stake 12 months after birth: Plos one scientific journal pone; 2016.11(3):e0151091.doi:10.1371.

28-Kaplan LA , Evans L, andMonk C. Effects of mothers prenatal psychiatric status and postnatal cargiving on infant bio behavioral regulation :can prenatal programming be modified ?Early human developmental research ; 2008,84(4):249-256

29-Lau R. and Morse C. Stress experiences of parents with premature infants in a special care nursery: Stress and Health Research ;2003,(19), 69-78.

30-Shin H, White-Traut R . The conceptual structure of transition to motherhood in the neonatal intensive care unit: Journal of Advanced Nursing . 2007; 58(1):90-8.

31-Sikorova L, Kucova J. The needs of mothers to newborns hospitalised in intensive care units: Biomed Paper of 
Medical Faculty University of Palacky Olomouc. 2012; 156(4):330-6.

32-Milkie E and Sarah M. Time with children ,s well-being , and work family balance among employed parents: journal of marriage and family ;2010,72 (5).

33-Ionio C. Post-traumatic stress symptoms after childbirthand early mother child interaction: An exp1orator study: Journa1 of Reproductive and Infant Psychology;2014, 32(3):163-181.

34-Melnyk B, Feinstein N, Alpert G. Reducing premature infant length of stay and improving parent mental health outcomes with the creating opportunities for parent empowerment (cope) neonatal intensive care unit program : a randomized,controlled trial. pediatrics Research; 2008,118(5): e1414-e1427.

\section{5-Malakouti J, Jebraeili M ,Valizadeh}

Sand babapour J. Mothers experience of having a preterm infant in the neonatal intensive care unit, a phenomenological study :iranian journal of critica 1 care nursing ;2012(4):172-181.

36-Sonia G, Natacha M, Elodie A, Brigitte B, Xavier D, et al. Parents' expectations of staff in the early bonding process with their premature babies in the intensive care setting: a qualitative multicenter study with 60 parents : BMC Pediatrics, BioMed Central, 2013, 13 (1), pp.18. $<10.1186 / 1471-2431-13-18>$.

37-RIIKKA I. Breast Milk for Preterm Infants Mothers' milk expressing experiences, practices, and coping strategies: Acta Universitatis Tamperensis 2349 Tampere University Press;2018, 1455-1616 (12).

38-Folkman S. Questions, answers, and next steps in stress and coping research: European Psychologist research; 2009. 14 (1), 72-77. 